\title{
PENGEMBANGAN APLIKASI PENGENDALIAN PERSEDIAAN OBAT DI APOTEK MENGGUNAKAN METODE HYBRID PERIODIC ORDER QUANTITY - MOVING AVERAGE
}

\author{
Gede Aditra Pradnyana1, I Made Arisetiawan Sunarya², Dewa Gede Hendra \\ Divayana $^{3}$
}

1 Universitas Pendidikan Ganesha

2 Universitas Pendidikan Ganesha

${ }^{3}$ Universitas Pendidikan Ganesha

\begin{abstract}
Abstrak
A pharmacy is a place of health service but indirectly also an effort to get the benefit. From the business point of view, of course, the pharmacy requires a system of processing inventory of goods, especially drugs - drugs in order to avoid losses. One of the pharmacies that have not optimally utilized the technology is at Apotek Karunia Asih located in Canggu Badung Bali. To overcome the problem of inventory control, at Apotek Karunia Asih requires inventory control application. The purpose of this research is to develop inventory control application with hybrid periodic order quantity - moving average method in Apotek Karunia Asih which gives benefit to the controlling of goods in pharmacies so that the goods and drugs sold in another are no longer past the expiration date, dead stock, stacking or stock shortages. Development of inventory control application with hybrid periodic order quantity - moving average method in Apotek Karunia Asih uses SDLC (Software Development Life Cycle) process to describe the stages in software development. SDLC process used is waterfall model. Waterfall model is a model that is systematic and sequential in building software, starting from the analysis, design, coding, testing, and support or maintenance. Implementation of this research is applied by using PHP programming language with the help of Codeigniter framework. For the testing process, five (5) test process stages are performed: (1) white box test which states that the source code implementation is appropriate and there is no error, (2) black box test to find out whether all software functional is appropriate, (3) test the suitability of the system to find out the correctness of the calculation process performed by the application, (4) the user response test which states the application and the methods used are very appropriate in controlling the supply of drugs in pharmacies; (5) the previous training test on forecasting that the previous training score will be used to predict the need is 6 because it has the smallest MAPE and MSE so that the forecasting results can be in accordance with the actual data.
\end{abstract}

\author{
Keywords: \\ Inventory Control, \\ Moving Average, Periodic \\ Order Quantity
}

\section{PENDAHULUAN}

Apotek adalah suatu tempat dilakukannya pelayanan kefarmasian, penyaluran sediaan farmasi, dan perbekalan kesehatan lainnya kepada masyarakat [1]. Meskipun apotek merupakan suatu tempat pelayanan kesehatan namun secara tidak langsung juga merupakan suatu usaha untuk mendapatkan benefit. Umumnya masalah yang timbul di apotek antara lain banyaknya obat yang melewati batas tanggal kedaluwarsa, stok mati, stok obat digudang menumpuk, dan kekurangan stok.

Tanggal kadaluwarsa dari suatu obat sangat bervariasi ada yang sangat dekat dari masa produksi ada juga yang cukup jauh. Dalam perjanjian pembelian ada beberapa obat yang mengalami kadaluwarsa dapat dikembalikan namun sebagian besar tidak. Pada akhirnya obat yang sudah kadaluwarsa tidak bisa dijual dan harus dimusnahkan. Stok mati adalah istilah yang biasanya digunakan untuk obat yang tidak laku dalam masa tiga bulan, hal ini dapat menimbulkan kerugian bagi pemilik dari usaha apotek karena jika terus dibiarkan ditakutkan akan menjadi obat expired. Stok yang menumpuk akibat dari jumlah pesanan yang tidak sesuai dengan obat yang keluar sedangkan stok kosong terjadi karena tidak mampu untuk memperkirakan jumlah obat yang keluar. 
Persediaan merupakan aset lancar terutama bagi perusahaan yang menanamkan sebagian besar asetnya adalah persediaan maka dibutuhkan pengelolaan persediaan yang baik. Tentunya tugas ini merupakan beban dari bagian menajemen perusahaan agar usaha tetap dapat beroperasi dengan lancar. Mengendalikan persediaan yang tepat bukan hal yang mudah, apabila jumlah persediaan terlalu besar mengakibatkan timbulnya dana menganggur yang besar, meningkatnya biaya penyimpanan, dan resiko kerusakan barang yang lebih besar. Namun jika persediaan terlalu sedikit mengakibatkan resiko terjadinya kekurangan persediaan karena seringkali bahan atau barang tidak dapat didatangkan secara mendadak dan sebesar yang dibutuhkan, yang menyebabkan kerugian pada perusahaan.

Salah satu apotek yang belum memanfaatkan teknologi secara optimal adalah di Apotek Karunia Asih yang terletak di daerah Canggu Badung Bali. Apotek Karunia Asih memiliki lebih dari 3000 jenis obat termasuk alat kesehatan. Banyaknya jenis obat yang dimiliki semakin menyulitkan untuk dilakukan pengendalian persediaan dan terlebih lagi untuk pengendalian persediaan hanya dilakukan dengan perkiraan saja. Kesulitan ini akan menimbulkan banyaknya obat yang melewati tanggal kedaluwarsa, jumlah stok obat yang berlebih maupun kekurangan stok obat yang nantinya akan dapat menyebabkan kerugian pada apotek.

Pada penelitian sebelumnya yang meneliti metode pengendalian persediaan terdapat beberapa metode dalam mengendalikan persediaan namun pada penelitian yang dilakukan Katarina Zita Anggriana (2015) menyimpulkan bahwa teknik Material Requirement Planning yang menghasilkan total biaya yang paling minimum adalah metode Periodic Order Quantity (POQ). Namun pada penelitian yang dilakukan Sungkono dan Sulistyowati (2016) metode ini juga memiliki kelemahan yaitu tidak dapat memberi tahu jumlah persediaan barang yang akan dipesan, maka pada penelitian yang dilakukan Irfan Abbas (2016) memberikan metode moving average sebagai peramalan kebutuhan karena mampu meramalkan tren terbaru selama periode waktu tertentu dengan menghitung bobotnya.

Namun pada penelitian sebelumnya tidak dijelaskan apakah mampu mengendalikan persediaan di apotek, tepatnya di apotek Karunia Asih. Maka untuk mengatasi masalah pengendalian persediaan di Apotek Karunia Asih membutuhkan aplikasi pengendalian persediaan. Sehingga akan akan dikembangkan aplikasi pengendaliaan persediaan dengan metode hybrid Periodic Order Quantity - Moving Average di Apotek Karunia Asih.

\section{METODE PENELITIAN}

Pengembangan aplikasi pengendaliaan persediaan dengan metode hybrid periodic order quantity moving average di Apotek KaruniaAasih menggunakan model waterfall yaitu model yang bersifat sistematik dan berurutan dalam membangun perangkat lunak, dimulai dari analisis, desain, pengodean, pengujian, dan tahap pendukung (support) atau pemeliharaan.

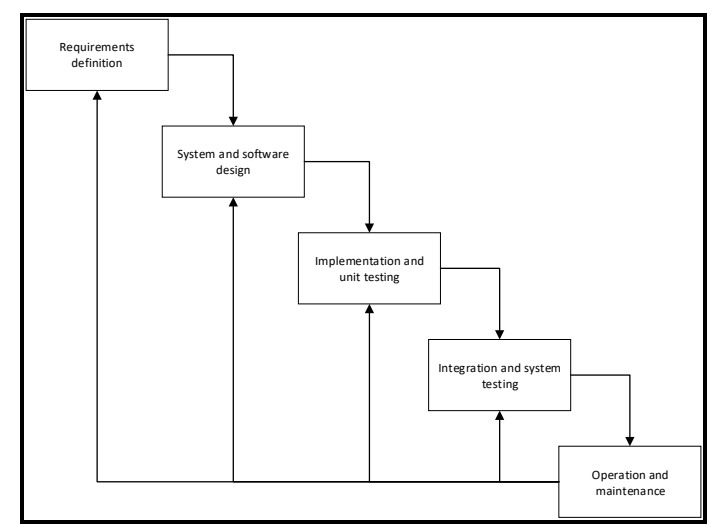

Gambar 1. Tahap model Waterfall [8]

Pengembangan aplikasi pengendaliaan persediaan dengan metode hybrid periodic order quantity moving average di Apotek Karunia Asih menggunakan model waterfall yaitu model yang bersifat sistematik dan berurutan dalam membangun perangkat lunak, dimulai dari analisis, desain, pengodean, pengujian, dan tahap pendukung (support) atau pemeliharaan.

Hasil wawancara dengan apoteker penganggung jawab apotek Karunia Asih yaitu Ni Luh Putu Oggi Yulianti, S.Farm, Apt beliau memaparkan bahwa pengendalian persediaan hanya dilakukan dengan 
perkiraan saja tanpa menghitung lebih detail total biaya dan kebutuhan akan persediaan. Hal ini menimbulkan banyaknya obat yang melewati tanggal kedaluwarsa, jumlah stok obat yang berlebih maupun kekurangan stok obat yang dapat menyebabkan kerugian pada apotek. Bagian persediaan sering merasa kesulitan dalam menentukan stok minimum suatu obat yang harus dipenuhi, kapan obat harus dipesan dan berapa jumlah pesanan optimalnya agar biaya persediaan dapat ditekan dan obat dapat berputar sehingga mengurangi timbulnya masalah - masalah persediaan obat.

Kebutuhan Fungsional, berdasarkan analisis dalam pengembangan ada beberapa kebutuhan fungsional dalam penelitian ini yaitu: a) Perangkat lunak ini dapat menampilkan tampilan dasar dari perangkat lunak, b) Perangkat lunak ini dapat menampilkan daftar data obat, c) Perangkat lunak ini dapat menampilkan informasi ramalan kebutuhan obat, d) Perangkat lunak ini dapat menampilkan informasi periodic order quantity (POQ), e) Perangkat lunak ini dapat memanajemen stok obat, f) Perangkat lunak ini dapat memanajemen data supplier.

Kebutuhan Non Fungsional, Kebutuhan non-fungional adalah kebutuhan yang tidak secara langsung terkait dengan fitur tertentu di dalam sistem. Kebutuhan non-fungsional yang dapat diperlukan sebagai berikut: a) Aplikasi pengendalian persediaan ini berbasis web dan dapat dijalankan pada komputer dengan prosessor core i3, hardisk 500GB dan memory 6GB, b) Aplikasi pengendalian persediaan dapat berjalan pada komputer dengan sistem windows 10 dengan bantuan berupa web browser

Tujuan pengembangan aplikasi pengendaliaan persediaan dengan metode hybrid periodic order quantity - moving average di Apotek Karunia Asih adalah sebagai berikut: a) Untuk merancang dan mengimplementasikan aplikasi pengendaliaan persediaan dengan metode hybrid periodic order quantity moving average di apotek Karunia Asih dalam mengendalikan persediaan obat, b) Untuk mengetahui respon pemilik dan karyawan terhadap aplikasi pengendaliaan persediaan dengan metode hybrid periodic order quantity - moving average di apotek Karunia Asih dalam mengendalikan persediaan obat.

Proses sistem pengendalian persediaan bertujuan untuk menentukan periode dan jumlah pemesanaan dengan metode yang telah ditentukan sesuai dengan analisis kebutuhan di Apotek Karunia Asih yaitu metode periodic order quantity (POQ) dan moving average (MA).

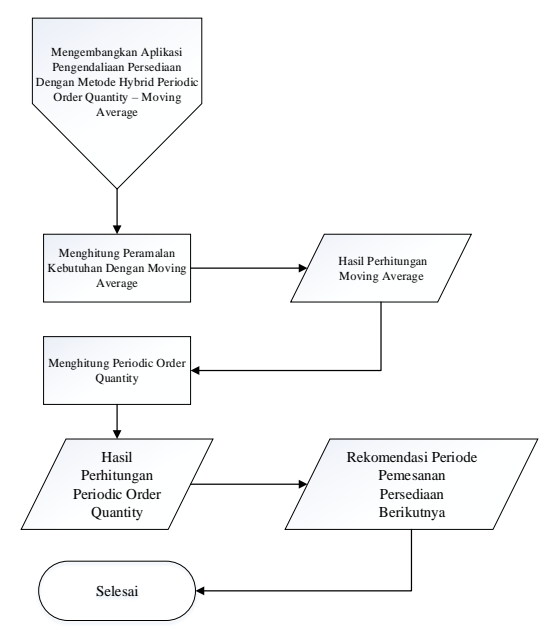

\section{Gambar 1. Flowchart Sistem Pengendalian Persediaan}

Menentukan periode dan jumlah pemesanan persediaan obat ditentukan dengan peramalan kebutuhan terlebih dahulu dengan metode moving average (MA) yang mengambil data penjuaalan obat sebelumnya sebagai input dan menghasilkan jumlah kebutuhan sebagai output yang menjadi input dalam perhitungan periodic order quantity (POQ). 


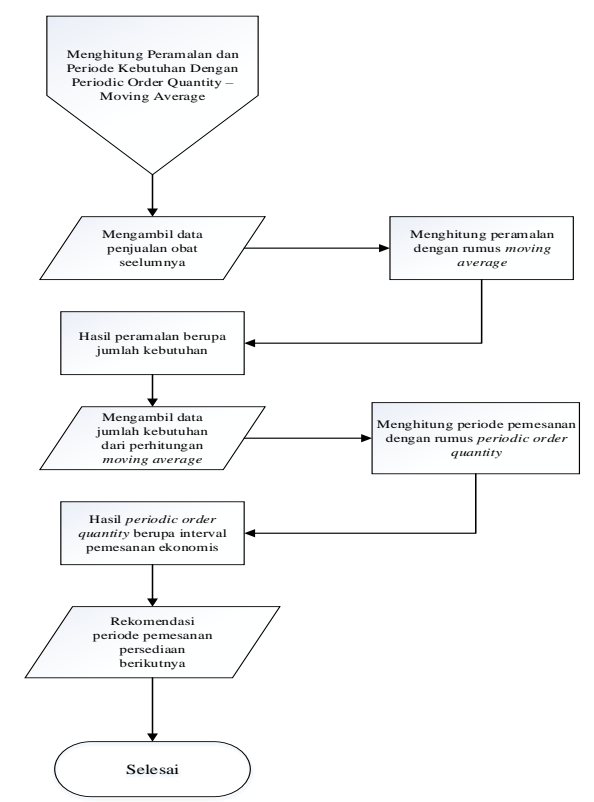

Gambar 2. Flowchart Menghitung Peramalan Dan Periode Pemesanan Dengan Moving Average - Periodic Order Quantity

Peramalan kebutuhan akan dipakai sebagai acuan dalam melakukan jumlah pemesanan per periode dan hasil POQ sebagai penentu periode pemesanan kembali dilakukan.

Sebagai contoh perhitungan manual metode hybrid periodic order quantity - moving average. Perhitungan manual ini bertujuan untuk pedoman yang nantinya digunakan dalam pembuatan sistem. Contoh perhitungannya adalah sebagai berikut:

Perhitungan manual dengan metode hybrid periodic order quantity - moving average menggunakan data history penjualan 3 bulan dari hasil transaksi yang pernah dicatat oleh karyawan Apotek Karunia Asih dan hanya mengambil satu sampel barang (obat) untuk proses perhitungan manual dengan biaya pesan 750000 rupiah dan biaya penyimpanan 1000 rupiah.

Tabel 1. Data Penjualan Paracetamol

\begin{tabular}{llllll}
\hline Nama Barang & Harga & Januari & Februari & Maret & Jumlah \\
\hline Paracetamol & 8000 & 30 Kotak & 28 Kotak & 24 Kotak & 65
\end{tabular}

Pertama yang dilakukan adalah menentukan kebutuhan hingga 12 periode menggunakan moving average dengan bobot 3 yang sesuai dengan persamaan 1. Dengan perhitungan sesuai dengan tabel 2 .

\begin{tabular}{|c|c|c|c|}
\hline No. & Bulan & Perhitungan & Hasil \\
\hline 1 & Januari & Data dari penjualan sebelumnya & 30 \\
\hline 2 & Februari & & 28 \\
\hline 3 & Maret & & 24 \\
\hline \multirow[t]{2}{*}{4} & April & $(30 x 1)+(28 \times 2)+(24 \times 3)$ & \multirow[b]{2}{*}{26,33333} \\
\hline & & 6 & \\
\hline \multirow[t]{2}{*}{5} & \multirow[t]{2}{*}{ Mei } & $(28 \times 1)+(24 \times 2)+(26,33 \times 3)$ & \multirow[b]{2}{*}{25,83333} \\
\hline & & 6 & \\
\hline
\end{tabular}




\begin{tabular}{|c|c|c|c|}
\hline \multirow[t]{2}{*}{6} & \multirow[t]{2}{*}{ Juni } & $(24 x 1)+(26,33 \times 2)+(25,833 \times 3)$ & \multirow[b]{2}{*}{25,69444} \\
\hline & & $\begin{array}{c}6 \\
\end{array}$ & \\
\hline \multirow[t]{2}{*}{7} & \multirow[t]{2}{*}{ Juli } & $(26,33 \times 1)+(25,833 \times 2)+(25,693 \times 3)$ & \multirow{2}{*}{25,84722} \\
\hline & & 6 & \\
\hline \multirow[t]{2}{*}{8} & Agustus & $(25,833 \times 1)+(25,693 \times 2)+(25,847 \times 3)$ & \multirow[b]{2}{*}{25,79398} \\
\hline & & $\begin{array}{l}6 \\
\end{array}$ & \\
\hline \multirow[t]{2}{*}{9} & September & $(25,693 \times 1)+(25,847 \times 2)+(25,793 \times 3)$ & \multirow[b]{2}{*}{25,79514} \\
\hline & & $\begin{array}{l}6 \\
\end{array}$ & \\
\hline \multirow[t]{2}{*}{10} & Oktober & $(25,847 \times 1)+(25,793 \times 2)+(25,795 \times 3)$ & \multirow[b]{2}{*}{25,80343} \\
\hline & & 6 & \\
\hline \multirow[t]{2}{*}{11} & November & $(25,793 \times 1)+(25,795 \times 2)+(25,803 \times 3)$ & \multirow[b]{2}{*}{25,79909} \\
\hline & & 6 & \\
\hline \multirow[t]{3}{*}{12} & Desember & $(25,795 \times 1)+(25,803 \times 2)+(25,799 \times 3)$ & \multirow[b]{2}{*}{25,79988} \\
\hline & & $\begin{array}{l}6 \\
\end{array}$ & \\
\hline & & JUMLAH & 314,6999 \\
\hline
\end{tabular}

Setelah mendapatkan jumlah kebutuhan dari perhitungan moving average (MA) yaitu 315 yang dibulatkan karena jumlah persediaan obat tidak ada yang bernilai desimal, maka selanjutnya jumlah kebutuhan tersebut masuk ke perhitungan periodic order quantity (POQ) sesuai dengan persamaan 2 bersama dengan biaya pemesanan dan biaya simpan untuk satu obat.

$$
P O Q=\sqrt{\frac{2 . S}{D . H}}=\sqrt{\frac{2 x 750.000}{315 \times 1000}}=2
$$

Jadi jumlah stok persediaan Parcetamol sebaiknya dipesan sebanyak 2 bulan sekali. Sesuai dengan perhitungan POQ yang dibulatkan karena periode pemesanan obat tidak ada yang bernilai desimal. Sehingga periode pemesanan sesuai dengan tabel 3.

Tabel 3. Hasil Perhitungan POQ

\begin{tabular}{ccccccccccccc}
\hline Periode & $\mathbf{1}$ & $\mathbf{2}$ & $\mathbf{3}$ & $\mathbf{4}$ & $\mathbf{5}$ & $\mathbf{6}$ & $\mathbf{7}$ & $\mathbf{8}$ & $\mathbf{9}$ & $\mathbf{1 0}$ & $\mathbf{1 1}$ & $\mathbf{1 2}$ \\
\hline Kebutuhan & 30 & 28 & 24 & 26 & 26 & 26 & 26 & 26 & 26 & 26 & 26 & 26 \\
\hline Jumlah & 58 & 0 & 50 & 0 & 52 & 0 & 52 & 0 & 52 & 0 & 52 & 0 \\
\hline
\end{tabular}

Dari tabel 3 diketahui pemesanan dilakukan setiap 2 bulan dengan jumlah pemesanan pertama yaitu sebanyak 58 yang didapatkan dari penjumlahan 2 bulan pertama lalu pemesanan kedua dilakukan setelah 2 bulan dari bulan pemesanan pertama dengan jumlah pemesanan sesuai kebutuhan setelah 2 bulan berikutnya. 
Untuk mentranslasi kebutuhan perangkat lunak ke representasi desain agar dapat diimplementasikan menjadi program pada tahap selanjutnya diperlukan use case diagram. Use case diagram digunakan untuk mewakili fungsionalitas dari sistem. Diagram ini menggambarkan interaksi antara pengguna, yang diwakili dengan notasi aktor, dengan sistem untuk mencapai tujuannya. Pada gambar 3 adalah use case diagram dari aplikasi pengendaliaan persediaan dengan metode hybrid periodic order quantity - moving average di Apotek Karunia Asih.

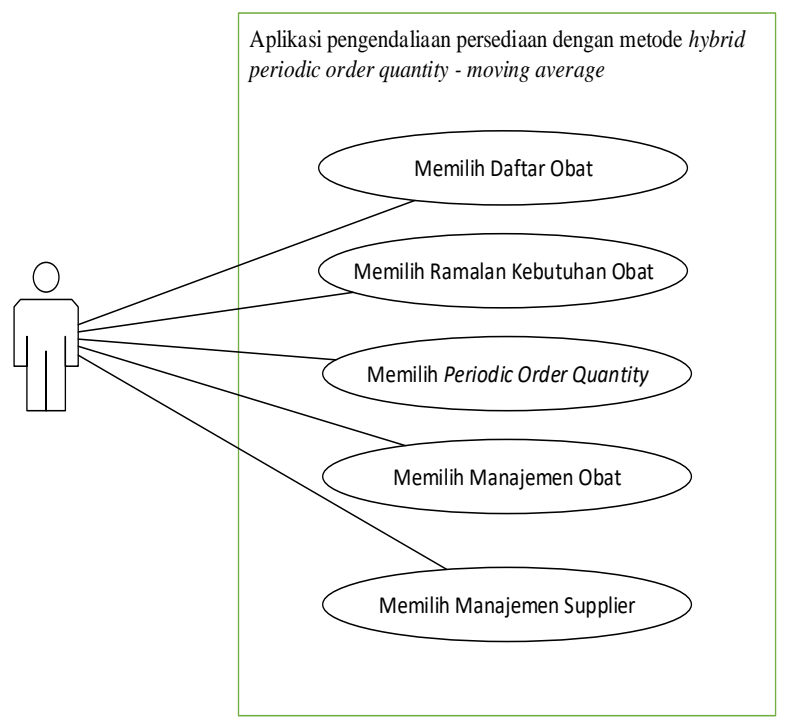

Gambar 3. Use case diagram.

\section{ANALISIS DAN PEMBAHASAN}

Hasil penelitian yang telah dilakukan dalam pengembangan aplikasi pengendaliaan persediaan dengan metode hybrid periodic order quantity - moving average di apotek karunia asih sebagai berikut. Hasil dari sistem pengendalian persediaan dijabarkan sebagai berikut.

Pengambilan data penjualan dilakukan di Apotek Karunia Asih yang berlokasi di Jalan Raya Canggu no 21 Badung. Dengan jumlah data 5 periode sebelumnya dan 4 periode yang akan datang. Yang mana 5 periode sebelumnya yaitu data penjualan persediaan selama 5 minggu dari tanggal 19 Juli sampai 31 Agustus 2017 untuk menghitung peramalan kebutuhan dan 4 periode dari tanggal 1 September sampai 30 September 2017 yaitu untuk mengetahui hasil dari perhitungan periodic order quantity yang sebelumnya di ramalkan dengan metode moving average.

Implementasi terdiri dari dua lingkungan, yaitu lingkungan implementasi perangkat keras dan lingkungan implementasi perangkat lunak. Spesifikasi yang digunakan dapat dilihat pada tabel 4 .

Tabel 4. Lingkungan implementasi perangkat lunak

\begin{tabular}{cc}
\hline \multicolumn{2}{c}{ Lingkungan Perangkat Keras } \\
\hline Prosessor & Intel $®$ Core i3 $-4000 \mathrm{M}$ \\
\hline RAM & $6 \mathrm{~GB}$ \\
\hline Harddisk & $500 \mathrm{~GB}$ \\
\hline \multicolumn{2}{c}{ Lingkungan Perangkat Lunak } \\
\hline Sistem Operasi & Microsoft Windows 10 \\
\hline Database & MySQL \\
\hline Bahasa Pemrograman & PHP (framework Codeigniter) \\
\hline Text Editor & Sublime Text 3 \\
\hline Web Server & Apache
\end{tabular}


Berdasarkan rancangan yang telah dibuat berikut adalah hasil implementasi perangkat lunak dalam penelitian ini yaitu

1. Hasil Antarmuka Perangkat Lunak

a. Hasil Antarmuka Tampilan Dasboard

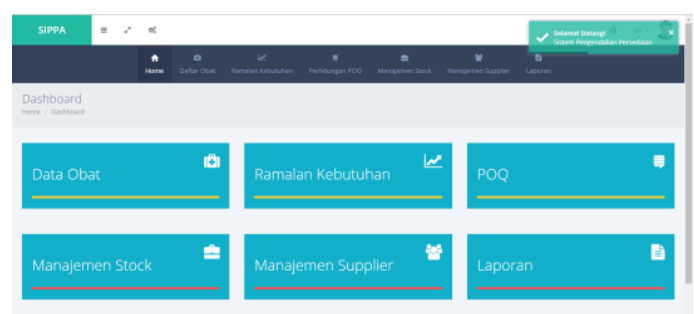

Gambar 4. Hasil Antarmuka Tampilan Dashboard

b. Hasil Antarmuka Tampilan Data Obat

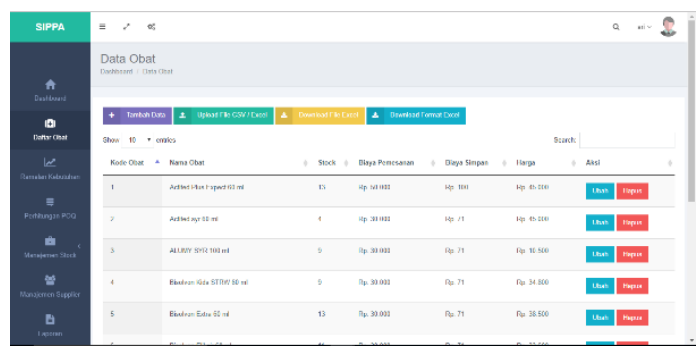

Gambar 5. Hasil Antarmuka Tampilan Mulai

c. Hasil Antarmuka Tampilan Halaman Peramalan

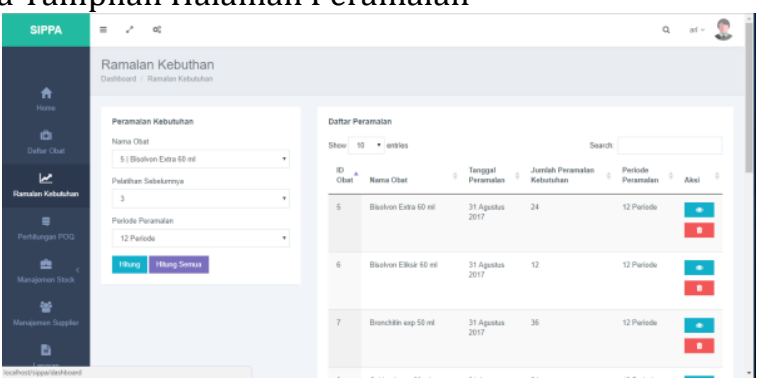

Gambar 6. Hasil Antarmuka Tampilan Halaman Peramalan

d. Hasil Antarmuka Tampilan Halaman Hasil Peramalan

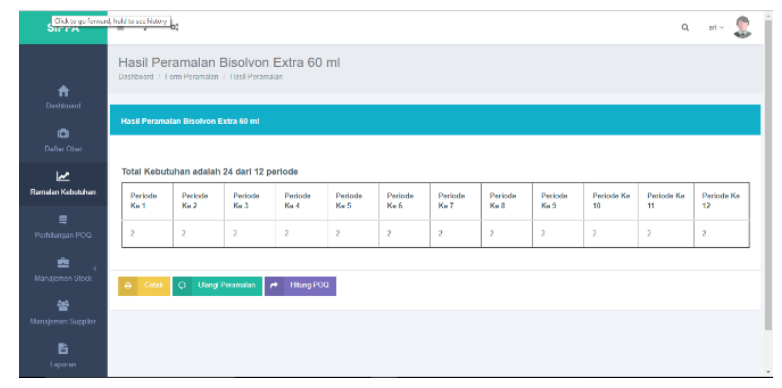

Gambar 7. Hasil Antarmuka Tampilan Halaman Hasil Peramalan

e. Hasil Antarmuka Tampilan Halaman Periodic Order Quantity 


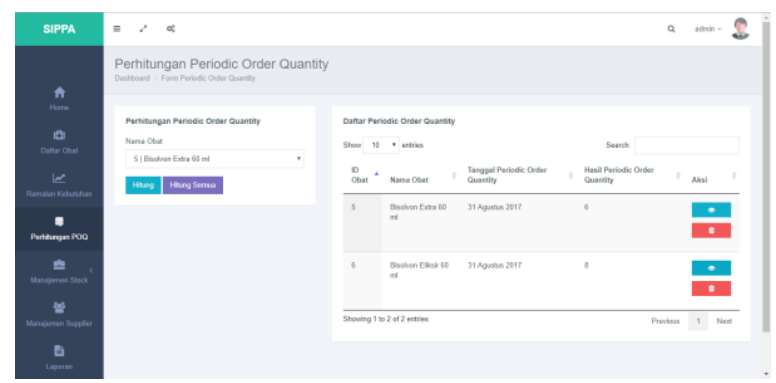

Gambar 8. Hasil Antarmuka Tampilan Halaman Periodic Order Quantity

\section{f. Hasil Antarmuka Tampilan Halaman Hasil Periodic Order Quantity}

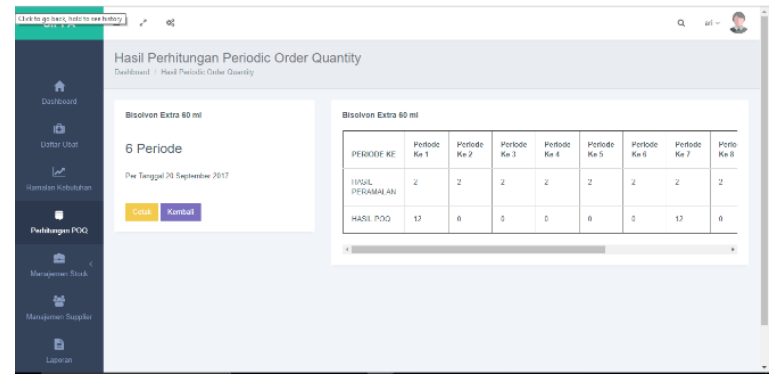

Gambar 9. Hasil Antarmuka Tampilan Halaman Hasil Periodic Order Quantity

\section{Hasil Pengujian Perangkat Lunak}

Berdasarkan rancangan yang telah dibuat berikut adalah hasil implementasi perangkat lunak dalam penelitian ini yaitu

1. Uji White Box

Pengujian white box bertujuan untuk menguji suatu aplikasi dengan cara melihat modul untuk dapat meneliti dan menganalisa kode dari program yang di buat ada yang salah atau tidak. Analisa yang dilakukan pada pengujian white box yaitu kesalahan logika, ketidaksesuaian asumsi, kesalahan pengetikan. Pengujian whitebox perangkat lunak berupa pengujian algoritma dilakukan oleh penulis pada hari Minggu, 20 Agustus 2017 pukul 18.00 WITA. Dari hasil pengujian whitebox untuk uji algoritma tersebut dapat dinyatakan bahwa semua algoritma yang digunakan untuk pembuatan Pengembangan Aplikasi Pengendaliaan Persediaan Dengan Metode Hybrid Periodic Order Quantity - Moving Average Di Apotek Karunia Asih sudah benar dan output sudah sesuai dengan tujuan dari masing-masing algoritma tersebut.

2. Uji Black Box

Black Box Testing merupakan pengujian yang berfokus pada spesifikasi fungsional dari perangkat lunak, penguji dapat mendefinisikan kumpulan kondisi input dan melakukan pengetesan pada spesifikasi fungsional program [8]. Pengujian black box bukan merupakan alternatif dari pengujian white box, tetapi merupkan komplementer yang kemungkinan besar mampu mengungkapkan kelas kesalahan daripada metode white box. Pengujian blackbox perangkat lunak ini dilakukan untuk menguji seluruh fungsional dari setiap form yang ada dalam aplikasi pengendaliaan persediaan dengan metode hybrid periodic order quantity - moving average di apotek Karunia Asih berjalan dengan baik. Pengujian ini dilakukan oleh peneliti sendiri pada hari Minggu, 20 Agustus 2017 pukul 20.00. Pengujian yang telah dilakukan menunjukkan hasil yang baik ditunjukan dengan semua fungsional form berjalan sesuai dengan kebutuhan fungsional yang telah dirancang sebelumnya.

3. Uji Kesesuaian Sistem

Pengujian kesesuaian sistem bertujuan untuk menguji kebenaran dari proses perhitungan yang dilakukan oleh aplikasi. Melalui uji kesesuaian sistem, aplikasi pengendaliaan persediaan dengan metode hybrid periodic order quantity - moving average di apotek Karunia Asih mendapatkan keyakinan tentang keefektifan aplikasi ini, sehingga data yang dihasilkan dapat digunakan dalam menyimpulkan suatu hasil. Dalam pengujian ini menggunakan data 1 obat dan data penjualan obat sebelumnya selama 5 periode yang akan dihitung secara manual dan sistem. 
Tabel 5. Hasil Peramalan Dihitung Secara Manual

\begin{tabular}{|c|c|c|c|}
\hline No & Perhitungan & Hasil & Pembulatan \\
\hline 1 & \multirow{5}{*}{$\begin{array}{c}\text { Data dari penjualan } \\
\text { sebelumnya selama } 5 \text { periode } \\
\text { dari tanggal } 19 \text { Juli sampai } 31 \\
\text { Agustus } 2017\end{array}$} & 1 & 1 \\
\hline 2 & & 1 & 1 \\
\hline 3 & & 2 & 2 \\
\hline 4 & & 2 & 2 \\
\hline 5 & & 3 & 3 \\
\hline
\end{tabular}

Kebutuhan Periode Selanjutnya

\begin{tabular}{|c|c|c|c|}
\hline \multirow[t]{2}{*}{1} & $15+8+6+2+1$ & 2,13333 & 2 \\
\hline & 15 & & \\
\hline \multirow[t]{2}{*}{2} & $10+12+6+4+1$ & 2,2 & 2 \\
\hline & 15 & & \\
\hline \multirow[t]{2}{*}{3} & $10+8+6+4+2$ & 2 & 2 \\
\hline & 15 & & \\
\hline \multirow[t]{2}{*}{4} & $10+8+6+6+2$ & 2,13333 & 2 \\
\hline & 15 & & \\
\hline \multirow[t]{2}{*}{5} & $10+8+6+4+3$ & 2,06666 & 2 \\
\hline & 15 & & \\
\hline \multirow[t]{2}{*}{6} & $10+8+6+4+2$ & 2 & 2 \\
\hline & 15 & & \\
\hline \multirow[t]{2}{*}{7} & $10+8+6+4+2$ & 2 & 2 \\
\hline & 15 & & \\
\hline \multirow[t]{2}{*}{8} & $10+8+6+4+2$ & 2 & 2 \\
\hline & 15 & & \\
\hline \multirow[t]{2}{*}{9} & $10+8+6+4+2$ & 2 & 2 \\
\hline & 15 & & \\
\hline \multirow[t]{2}{*}{10} & $10+8+6+4+2$ & 2 & 2 \\
\hline & 15 & & \\
\hline \multirow[t]{2}{*}{11} & $10+8+6+4+2$ & 2 & 2 \\
\hline & 15 & & \\
\hline \multirow[t]{3}{*}{12} & $10+8+6+4+2$ & 2 & 2 \\
\hline & 15 & & \\
\hline & Total Kebutuha & & 24 \\
\hline
\end{tabular}

Tabel 6. Hasil Periode Pemesanan Dihitung Secara Manual

\begin{tabular}{ccc}
\hline No. & Kebutuhan & Pemesanan \\
\hline 1 & 2 & 12 \\
2 & 2 & 0 \\
3 & 2 & 0 \\
4 & 2 & 0 \\
5 & 2 & 0 \\
6 & 2 & 0 \\
7 & 2 & 12 \\
8 & 2 & 0 \\
9 & 2 & 0 \\
10 & 2 & 0 \\
11 & 2 & 0 \\
12 & 2 & 0 \\
\hline
\end{tabular}

Jika dibandingkan dengan hasil perhitungan aplikasi pengendaliaan persediaan dengan metode hybrid periodic order quantity - moving average di apotek Karunia Asih juga memiliki hasil yang sama seperti terlihat pada Gambat 16 dan Gambar 17, maka hasil pengujian kesesuaian sistem dinyatakan lulus. 


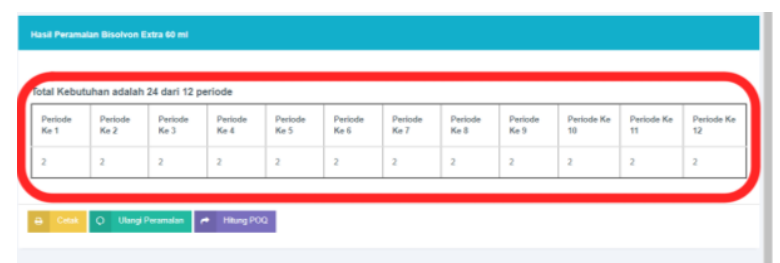

Gambar 10. Hasil Peramalan Dengan Sistem

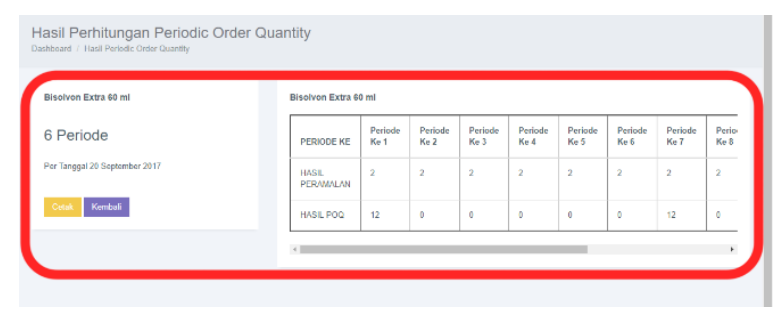

Gambar 11. Hasil Periode Pemesana Dengan Sistem

4. Uji Respon Pengguna

Pengujian ini bertujuan untuk mengetahui kebermanfaatan sistem yang dikembangkan oleh peneliti. Pengujian yang dilakukan pada tanggal 29 - 31 September 2017 dengan melibatkan pengguna yang akan berinteraksi dengan Sistem ini. Adapun pengguna yang dilibatkan adalah 5 orang karyawan dan 1 orang apoteker penanggung jawab apotek Karunia Asih.

Tabel 7. Data Hasil Uji Respon Pengguna

\begin{tabular}{|c|c|c|c|c|c|c|}
\hline \multirow{2}{*}{$\begin{array}{c}\text { Fokus } \\
\text { Penilaian }\end{array}$} & \multicolumn{6}{|c|}{ Responden } \\
\hline & 1 & 2 & 3 & 4 & 5 & 6 \\
\hline $\begin{array}{c}\text { Pernyataan } \\
1\end{array}$ & 5 & 5 & 4 & 5 & 5 & 5 \\
\hline $\begin{array}{c}\text { Pernyataan } \\
2\end{array}$ & 5 & 3 & 3 & 4 & 3 & 4 \\
\hline $\begin{array}{c}\text { Pernyataan } \\
3\end{array}$ & 5 & 5 & 4 & 5 & 5 & 4 \\
\hline $\begin{array}{c}\text { Pernyataan } \\
4\end{array}$ & 5 & 5 & 5 & 5 & 5 & 5 \\
\hline $\begin{array}{c}\text { Pernyataan } \\
5\end{array}$ & 5 & 5 & 4 & 5 & 5 & 5 \\
\hline $\begin{array}{c}\text { Pernyataan } \\
6\end{array}$ & 5 & 5 & 5 & 5 & 5 & 4 \\
\hline $\begin{array}{c}\text { Pernyataan } \\
7\end{array}$ & 5 & 4 & 3 & 4 & 4 & 4 \\
\hline $\begin{array}{c}\text { Pernyataan } \\
8\end{array}$ & 5 & 5 & 5 & 5 & 5 & 5 \\
\hline $\begin{array}{c}\text { Pernyataan } \\
9\end{array}$ & 5 & 5 & 5 & 5 & 5 & 5 \\
\hline $\begin{array}{c}\text { Pernyataan } \\
10\end{array}$ & 4 & 5 & 5 & 5 & 5 & 5 \\
\hline JUMLAH & 49 & 47 & 43 & 48 & 47 & 46 \\
\hline PRESENTASE & $\mathbf{9 8} \%$ & $94 \%$ & $86 \%$ & $96 \%$ & $94 \%$ & $92 \%$ \\
\hline
\end{tabular}

Dari data hasil uji respon pengguna selanjutnya dihitung persentase hasil untuk mengetahui kebermanfaatan sistem yang dikembangkan oleh peneliti dan perhitungannya adalah sebagai berikut:

Persentase Hasil $=\frac{\sum F}{N}=\frac{560 \% 6}{6}=93,33 \%$ 


\section{Uji Pelatihan Sebelumnya Pada Peramalan}

Dalam melakukan peramalan terdapat sejumlah indikator untuk pengukuran akurasi peramalan, tapi yang paling sering dilakukan adalah MAPE (Mean Absolute Percentage Error = rata-rata persentase kesalahan absolut), MSE (Mean Square Error = rata-rata kuadrat kesalahan.

Akurasi peramalan akan semakin tinggi apabila nilai MAPE, dan MSE semakin kecil. MAPE adalah persentase kesalahan hasil peramalan terhadap permintaan aktual selama periode tertentu yang akan memeberikan informasi persentase kesalahan terlalu tinggi atau terlalu rendah. MSE merupakan penjumlahan kuadrat semua kesalahan peramalan pada setiap periode dan membaginya dengan jumlah periode peramalan [3].

Untuk menghitung nilai MAPE dan MSE dapat dihitung sebagai berikut:

$$
\begin{gathered}
M A P E=\frac{1}{n} \sum_{t=1}^{n}\left(\frac{A t-F t}{A t}\right) \\
M S E=\frac{1}{n} \sum_{t=1}^{n}(A t-F t)
\end{gathered}
$$

Dalam persamaan 3 dan 4, $\mathrm{n}$ adalah banyaknya periode peramalan dan At merupakan data aktual atau data sebenarnya sedangkan Ft adalah data hasil peramalan.

Pada pengujian ini peneliti mendapatkan bahwa nilai pelatihan sebelumnya 6 adalah nilai yang terbaik karena memiliki MAPE dan MSE terkecil yaitu 0,0032 dan 1. Hal ini dapat dilihat pada gambar 18 dan gambar 19.

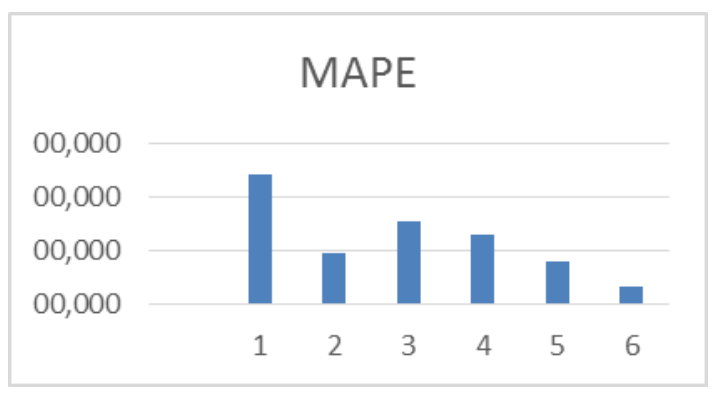

Gambar 12.Grafik MAPE

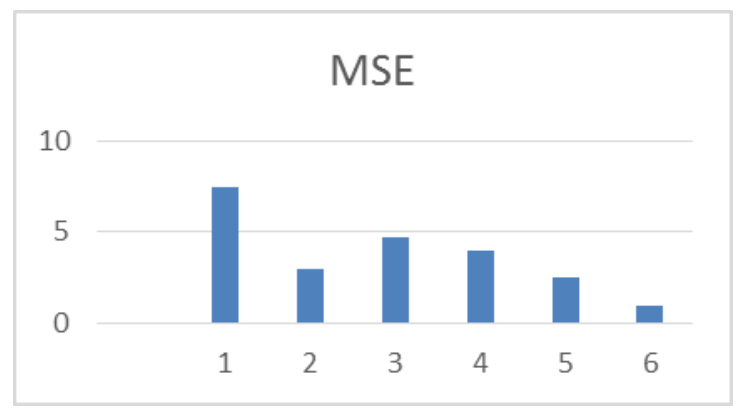

Gambar 13.Grafik MSE

Aplikasi Pengendaliaan Persediaan Dengan Metode Hybrid Periodic Order Quantity - Moving Average di Apotek Karunia Asih dirancang menggunakan bahasa pemrograman PHP dalam hal ini yaitu framework codeigniter dan dijalankan dalam sistem operasi windows 10 dengan database MySQL dan web server Apache. Pada aplikasi ini pengguna meramalkan kebutuhan persediaan terlebih dahulu yang dihitung menggunakan metode moving average dari data penjualan sebelumnya kemudian menghitung periode pemesanan dengan metode periodic order quantity.

Pada saat peramalan menggunakan metode moving average yang diperlukan adalah data penjualan sebelumnya, nilai pelatihan sebelumnya untuk menentukan bobot peramalan dan batasan periode peramalan. Sehingga data selain itu tidak diperhatikan. Dan selanjutnya adalah menghitung periode pemesanan dengan metode periodeic order quantity dari data peramalan yang sudah dihitung dengan metode moving average sehingga menghasilkan periode pemesanan selanjutnya dan jumlah pemesanan yang optimal. 
Pengujian aplikasi dilakukan untuk mengetahui kesalahan pada pengkodean dan fungsional dari aplikasi. Selain itu pengujian juga digunakan untuk mengetahui seberapa baik metode yang digunakan aplikasi dalam mengatasi masalah yang dialami apotek Karunia Asih dalam mengendalikan persediaan.

Pengujian yang pertama dilakukan adalah pengujian white box. Pengujian white box bertujuan untuk menguji aplikasi dengan cara melihat modul untuk dapat menganalisa kode dari program yang di buat ada yang salah atau tidak. Berdasarkan pengujian white box, aplikasi sudah benar dan output sudah sesuai dengan algoritmanya. Kedua adalah pengujian black box yang bertujuan untuk menguji fungsionalitas form dalam aplikasi. Berdasarkan pengujian black box, fungsionalitas dari form aplikasi sudah sesuai dengan kebutuhan fungsional. Selanjutnya adalah pengujian kesesuaian sistem yang menghasilkan bahwa perhitungan yang dilakukan aplikasi sudah sesuai dengan perhitungan manual.

Pengujian berikutnya adalah pengujian respon pengguna, dengan membandingkan data persentase hasil pengujian maka dapat disimpulkan bahwa Aplikasi Pengendaliaan Persediaan Dengan Metode Hybrid Periodic Order Quantity - Moving Average di Apotek Karunia Asih dapat dikatakan berhasil dan dalam kategori sangat sesuai dengan hasil 93,33\% yang berarti bahwa sistem dapat mengatur persediaan apotek dari sisi pengguna. Pengujian yang terakhir adalah pengujian pelatihan sebelumnya pada permalan yang menghasilkan bahwa pelatihan 6 memiliki nilai MAPE dan MSE yang paling kecil dan mendekati data aktual atau data sebenarnya sehingga apoteker atau karyawan dapat meramalkan kebutuhan dengan nilai pelatihan sebelumnya 6 sehingga mengurangi kerugian dalam pemesanan dari peramalan kebutuhan persediaan apotek.

\section{KESIMPULAN}

Berdasarkan hasil analisis, implementasi dan pengujian pada penelitian pengembangan Aplikasi Pengendaliaan Persediaan Dengan Metode Hybrid Periodic Order Quantity - Moving Average di Apotek Karunia Asih dapat ditarik kesimpulan bahwa dirancang menggunakan bahasa pemrograman PHP dalam hal ini yaitu framework codeigniter dan dijalankan dalam sistem operasi windows 10 dengan database MySQL dan web server Apache dan telah berhasil dalam mengendalikan persediaan obat di apotek Karunia Asih sehingga dapat membantu dan mempermudah karyawan dalam mengatur persediaan obat yang dibuktikan dengan pengujian menggunakan metode White Box, Black Box dan Respon Pengguna dengan rata-rata respon pengunaan tertinggi sebesar 93,33\% pada pengujian juga memiliki MAPE dan MSE yang kecil sebesar 0,0032 dan 1 yang berarti hasil dari perhitungan aplikasi dengan data sebenarnya tidak jauh berbeda.

Berdasarkan hasil penelitian pengembangan dan kesimpulan, dapat disarankan bagi pembaca yang ingin mengembangkan aplikasi ini sebagai berikut: 1) Diharapkan dapat menguji dengan data penjualan selanjutnya yang lebih banyak. Karena peneliti kekurangan waktu untuk menguji bobot pelatihan sebelumnya, 2) Menggunakan metode pengendalian yang lain seperti Lot For Lot, Economic Order Quantity atau mengkombinasikannya dengan metode lain agar pengendalian persediaan dapat lebih menghemat biaya, waktu, dan akurasi dengan data aktual semakin besar, 3) Dapat menggunakan metode lain selain metode moving average untuk menghitung peramalan, sehingga faktor seperti musim atau cuaca dan wabah penyakit dapat diperhitungkan. Dan membuat peramalan kebutuhan semakin akurat dengan data sebenarnya, 4) Besar harapan aplikasi ini bisa dikembangkan untuk digunakan oleh apotek lain atau bahkan dikembangkan untuk usaha - usaha yang memerlukan sistem pengendalian persediaan.

\section{DAFTAR PUSTAKA}

Z. Yamit, Manajemen Persediaan, Yogyakarta: EKONISIA Fakultas Ekonomi UII, 2008.

I. Abbas, "Penerapan Metode Moving Average (MA) Berbasis Algoritma Support Vector Machine (SVM) Untuk Membandingkan Pola Kurva Dengan Trend Kurva Pada Trading Forex Online," Jurnal Ilmiah ILKOM, Vol. 8, No. 1, pp. 37-43, 2016.

K. Z. Anggriana, "Analisis Perencanaan Dan Pengendalian Persediaan Busbar Berdasarkan Sistem MRP (Material Requirement Planning) Di PT. TIS," Jurnal PASTI, Vol. 9, No 3, pp. 320-337, 2015.

M. A. Sungkono and W. Sulistyowati, "Perencanaan Dan Pengendalian Bahan Baku Untuk Meningkatkan Efisiensi Produksi Dengan Metode Material Requirement Planning Dan Analytical Hierarchy Process Di PT. XYZ," Spektrum Industri, Vol. 14, No. 1, pp. 1-108, 2016.

Kementrian Kesehatan, Peraturan Menteri Kesehatan Republik Indonesia No. 35 Tahun 2014 tentang Standar Pelayanan Farmasi di Apotek, Jakarta: Menteri Kesehatan, 2014. 
A. Kristanto, Rekayasa Perangkat Lunak (Konsep Dasar), Yogyakarta: Gava Media, 2004.

PT. Proweb Indonesia, "Website Adalah," 19 Maret 2017. [Online]. Available: http://www.proweb.co.id/articles/web_design/website_adalah.html.

W. Hastomo, "Pengertian dan Kelebihan Database MySQL," 19 Maret 2017. [Online]. Available: http://hastomo.net/php/pengertian-dan-kelebihan-database-mysql/.

D. A. Hadi, "Pengertian dan Cara Menggunakan Codeigniter," 19 Maret 2017. [Online]. Available: http://www.malasngoding.com/pengertian-dan-cara-menggunakan-codeigniter/.

P. Roger S. Pressman, Rekayasa Perangkat Lunak Pendekatan Praktisi (Edisi 7 : Buku I), Yogyakarta: ANDI, 2012. 